\title{
To draw or not to draw: Informed consent dilemma
}

\author{
Santovito $\mathrm{D}^{1 *}$, Cena $\mathrm{G}^{2}$, Tattoli $\mathrm{L}^{1}$, Di Vella $\mathrm{G}^{2}$ and Bosco $\mathrm{C}^{2}$ \\ ${ }^{1}$ S.C. Medicina Legale U, A.O.U. Città della Salute e della Scienza di Torino, Torino, Italy \\ ${ }^{2}$ Department of Public Health and Pediatrics, Section of Legal Medicine, University of Turin, Torino, Italy
}

\begin{abstract}
Background: Informed consent is a worldwide standard medical practice. The purpose of this study was to determine whether surgical freehand-drawings do facilitate surgeons in the communication process.

Methods: Authors carried out a questionnaire survey aimed at exploring physicians' perceptions of the usefulness of drawings, in terms of level of understanding in consent acquisition procedures. A total of 90 anonymous questionnaires were distributed for doctors to fill in, in surgical and interventional medicine wards of the University Hospital of Turin.

Results: Out of the 90 questionnaires delivered, 37.8\% ( $n=34)$ were filled out. $93.8 \%(n=30)$ of the physicians interviewed consider freehand-drawings a useful tool, $90 \%(n=27)$ of the surgeons, who confirmed to routinely use drawing for informed consent acquisition purposes. $96.3 \%$ ( $n=26$ ) of the physicians who draw themselves illustrative images of proposed treatments asserted to perceive a real benefit in patients' comprehension of the information when visually provided. Many respondent surgeons stated to consider drawing an effective means of information for consent acquisition. Nonetheless, just in $7.4 \%$ of the cases, personally drawn explicative images are then added in patients' medical records, with possible detrimental effects on a medico legal point of view.

Conclusions: Graphical representation is useful for breaking down comprehension barriers resulting not only from the modality in which the information is conveyed but also from patients' relational, social, and psychological factors, ensuring bi-directionalness of communication and prove in Italy, a Civil Law Country, the communicative effort of physicians in the best interest of the patients.
\end{abstract}

\section{Introduction}

Informed consent is a worldwide standard medical practice. The lawfulness of any medical act is in fact guaranteed only by patient's consent, which consists of three essential elements: information, comprehension, and voluntariness [1]. A doctor's obligation is to ensure the patient is both conscious of the nature, goals and consequences of the treatments proposed and in agreement with the procedures he or she will undergo [2]. Although consent form signing is a routine occurrence in healthcare settings, only a limited number of studies report the effective validity of them [3]. All too often the informed consent is a standardized form, bearing generic or excessively technical information, particularly affecting the patient's understanding of possible complications associated with procedures.

Other potential confounding issues of the efficacy of informed consent are related to communication barriers. In fact, in multicultural society, it has become increasingly common for physicians to treat patients who have difficulty speaking and understanding Italian. Even without language barriers, a gap still exists between doctors and patients in the communication-comprehension of medical information. Most clinical conditions and therapeutic options are in fact complicated making it difficult for patients to fully understand the pathogenesis, and prognosis of the disease they are affected by and its possible treatment [4]. Because of the complexity of the matter, the terms used in medical settings are often technical and, quite hard for the average person to understand, especially when the targets are people with poor levels of literacy, such as like minors or immigrants. Emergency conditions further widen this gap, as patients and their family show difficulties in understanding what will happen under time constraints, as with surgical procedures.
Medical illustrations demonstrating clinical conditions, including their pathogenesis and treatment, or therapeutic procedures may aid intuitive, quick and comprehensive acquisition of informed consent. However, research examining, by the surgeon perspective, the actual advantages of the use of explicative medical drawing images, referring to schematic/quick drawings made in real time in clinical situations for patients, have not yet been conducted.

Italy is a civil law country, and informed consent is regulated by a specific law as malpractice judgment [5]. The Authors evaluated only the point of view of the surgeon through a questionnaire survey to investigate whether freehand drawings facilitate the surgeon in obtaining informed consent. A sample of physicians were interviewed about the use of freehand drawings for consent purposes in medical settings and, when used, whether that visual communicative modality is documented in the medical records of patients.

\section{Methods}

Authors carried out a questionnaire survey aimed at exploring only physicians' perceptions of the usefulness of medical drawings, in terms

${ }^{\star}$ Correspondence to: Santovito Davide. A.O.U. Città della Salute e della Scienza di Torino, S.C. Medicina Legale U., Corso Bramante 88, Torino, Italy, Tel +390116336972; Email: dsantovito@cittadellasalute.to.it

Key words: informed consent, patients'self-determination, medical drawing, medical sketch, medical record, medical malpractice

Received: May 03, 2021; Accepted: May 12, 2021; Published: May 14, 2021 
of efficiency and level of understanding, when conveying information to patients in consent acquisition procedures. Authors defined medical drawing as freehand drawing.

Within the first two weeks of August 2019, a total of 90 anonymous questionnaires were distributed to doctors from different surgical wards of the University Hospital "Città della Salute e della Scienza" of Turin, including: general surgery, vascular surgery, maxillo-facial surgery, plastic surgery, cardio-thoracic surgery, urology, otorhinolaryngology, interventional radiology, gastroenterology endoscopy and anesthesiology. The distributed questionnaires, an example of which is shown in Figure 1, consisted of two questions. In the first one, it was asked if the physician had ever thought of using drawings to inform patients when collecting informed consent; only if the answer was negative, the questionnaires were numbered from one to 90 in order to avoid duplication when counting. Doctors were required to answer the two questions (each one had two possible mutually exclusive answers: yes or no). After 15 days from the moment of the distribution, the questionnaires

ANONIMOUS QUESTIONNAIRE

MEDICAL SPECIALTY OF BELONGING

QUESTION N.1

Have you ever considered to use drawing to inform patients in order to guarantee a truly informed consent?

YES NO

1.a) If you answered NO to the previous question, do you deem drawing a useful tool for providing information to patients? YES NO

\section{QUESTION N.2}

Do you sketch yourself the explanatory drawing of invasive procedures to patients?

YES NO

If you answered YES to the previous question:

2.a) is the drawing added in patients' medical record as standard routine?

YES

NO

2.b) Do you perceive a real benefit in patients' comprehension of information when it is conveyed through drawing?

YES

NO

Figure 1. The questionnaire 
were collected and analyzed. Forms not fully completed were excluded from the study.

\section{Results}

Out of the 90 questionnaires delivered, $34(37 \bullet 8 \%)$ were filled out; of these, two were discarded due to errors in the compilation process.

The analysis of the answers to question 1 in the 32 deemed valid questionnaires revealed that $93.8 \%(30 / 32)$ of the physicians interviewed consider drawing a useful tool in providing adequate information to patients (an example in Figure 2).

In all $90 \%(27 / 30)$ of the clinicians, who confirmed to routinely using drawing for informed consent acquisition purposes, claimed to sketch in real-time by themselves explanatory images of invasive procedures to patients (question 2). Of these, just $6 \cdot 7 \%(2 / 27)$ stated adding them in medical records as an integral component of consent documentation, certificating that adequate information was provided to patients (question 2a). The remaining 10\% (3/30) of physicians rely on standard pictures contained in pre-printed consent forms.
A total of $96 \cdot 3 \%(26 / 27)$ of the physicians who themselves drew illustrative images of proposed treatments claimed to perceive a real benefit in patients' comprehension of the information when visually provided.

The results of the survey are summed up in a schematic fashion in Figure 3.

\section{Discussion}

Informed consent represents the legal foundation for any medical procedure [6], as well as a tool to promote patients' constitutionally guaranteed right to self-determination (Articles 2, 13, 32 of the Italian Constitution) [7]. Informed consent provides patients with the opportunity to decide what is in their own best interests, recognizing each individual's value system, beliefs, and life goals and how these factors affect their decision-making process. When adequate information is provided, patients can only fully assert their right to selfdetermination by choosing whether or not to partake in a proposed therapeutic process. Given its known risks [8] they take their part of responsibilities in the "therapeutic alliance" with physicians [9].
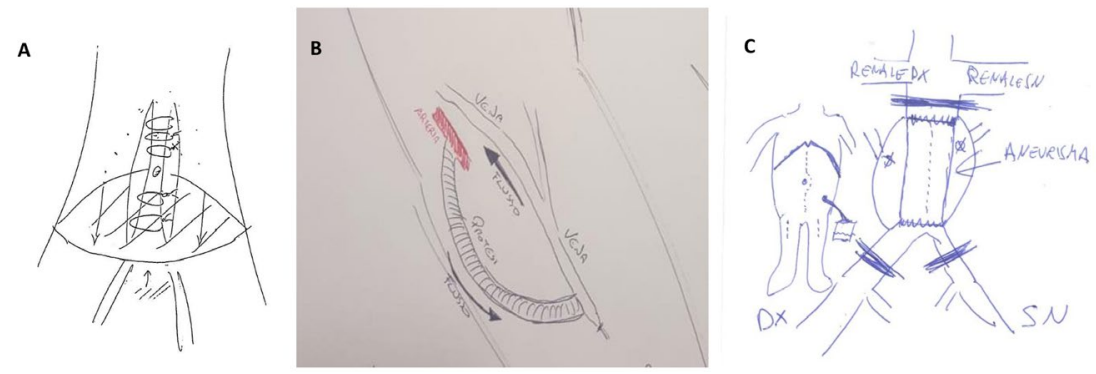

Figure 2. Surgical freehand drawing examples

A - Drawing of surgical abdominoplasty and rectus abdominis diastasis; oblique lines show the tissue the surgeon will remove and the arrows show how the superior and inferior incision lines will suture together; the little circle in the center is the belly button on the linea alba, while the other five circles represent the correction of abdominis diastasis.

B - Drawing of arteriovenous fistula confection with prosthesis for hemodialysis; vena: vein; flusso: flow; protesi: prosthesis; and arteria: artery.

C - Drawing of abdominal aortic aneurysm surgical repair with Dacron prosthesis; dashed lines are surgical incisions; dx: right, sn: left; aneurisma: aneurysm; renale dx: right renal artery; and renale sn: left renal artery.

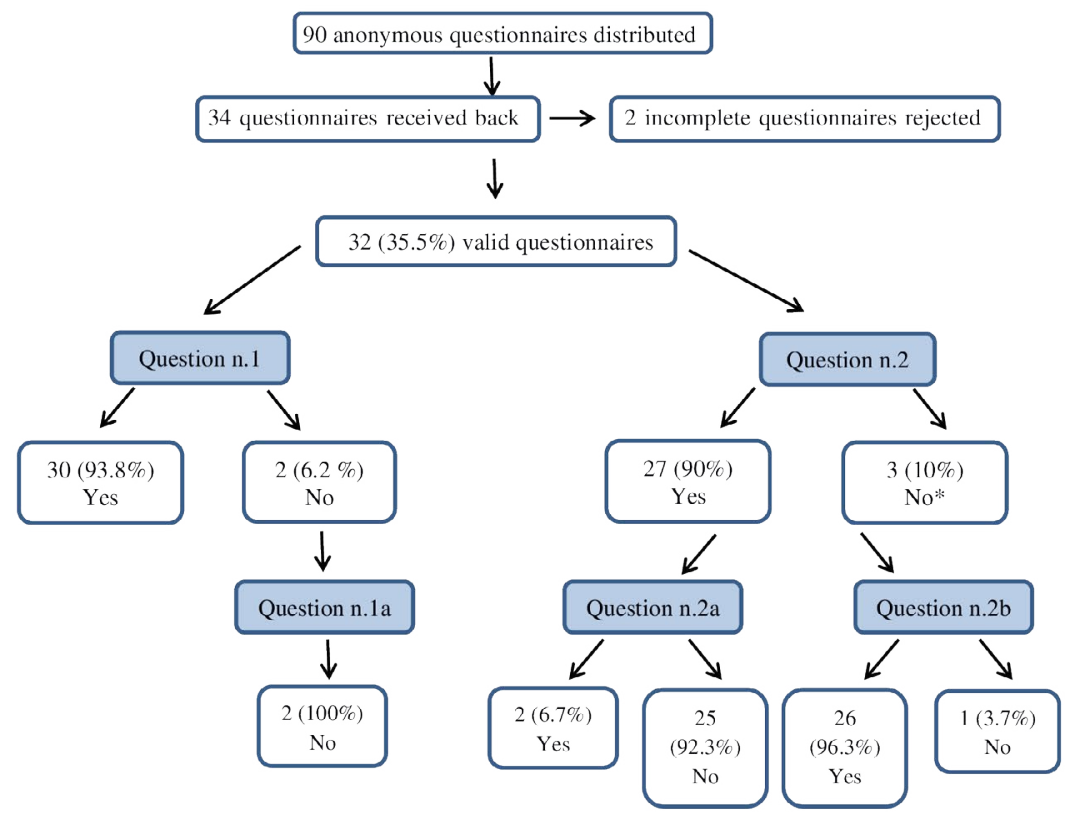

Figure 3. Results of the survey

*2 answers "No" from Question n. 1 and 3 answers "No" from Question n.2. Total number of answers to Question n.2 is 30 
The importance of consent is further stressed in the Italian Code of Medical Deontology [10] as defined in Article 33, without prior acquisition of informed consent from patients or in case of their explicit dissent, no diagnostic procedure and/or therapeutic intervention must be undertaken or further pursued.

In 2017, with the implementation of Law n. 219 ("Norme in materia di consenso informato e di disposizioni anticipate di trattamento", i.e norms in the matter of informed consent and advance directives of treatment), Italian Parliament further enshrined the central importance of informed consent: patients are considered active subjects in the therapeutic relationship with doctors and the health care system too, ensuring that no prejudice is caused to their decisionmaking autonomy. Moreover, since 2017, the time needed to provide the necessary information rightfully falls by law within patient "cure time", therefore, consent is to be considered the culmination of a long-informed cure decision-making process involving patients as much as physicians [11]. This is true also for other countries, such as the USA [12]. The purpose is ensuring a strong human doctor-patient relationship [13] through a series of interventions aimed at improving information-sharing and increasing patient satisfaction $[14,15]$.

Correct and comprehensive information is the key validity requirement to guarantee that patients make conscious and autonomous choices about their own health. No signature on a standard consent form, bearing generic or excessively technical information, can thus be deemed lawfully adequate [16].

Therefore, physicians must find the most appropriate formula to inform patients in a comprehensible, exhaustive and practical way in order to guarantee a truly informed consent [17]. The language used to convey information must be simple [18] and adapted to the cultural level and comprehension skills of each individual patient [19].

Sometimes though, even taking these necessary precautions, it's difficult to ascertain whether the patient genuinely understood the information verbally provided. This is especially true for surgical contexts in which communication time is particularly critical due to the generally frail conditions of the patients [20], the urgent nature of the procedures and the variety of factors that may endanger the lives of patients, including the risks inherent to the treatment itself. Although many studies have investigated the patients' quality of understanding of information through interviews or questionnaires [21], just a few have focused on the surgical ones. A systematic review focused on this specific group of patients identified that only $29 \%$ of them adequately understood the verbal information provided about the invasive procedure and the related risks when undergoing surgery [22]. Studies have shown a better understanding and consequently a more informed consent when the information was written rather than orally communicated. In anxious contexts, the ability to be able to read the information as many times as needed, with the support of familiar figures where needed, can be useful for patients to process the complexity of the information conveyed.

Still, standard pre-printed models, although written, are considered inappropriate for consent purposes. On this matter, the Court of Cassation recognized the inadequacy of patients' subscription of a generic form since "consent must always be considered the result of a real relationship established between doctor and patient, in which the latter must express their genuine and participatory adherence to the proposed therapeutic project"; all of that cannot be reduced to a simple signature on a paper [21].
In this regard, a recent judgment of the Italian Court of Cassation emphasized the value of drawings when informing patients about the risks of specific treatments [23]. In the medical literature, the usefulness of illustrations is widely recognized as a tool for simplifying communication and making information accessible for every patient [24]. This is especially true when it's required to convey technical explanations of surgical procedures in a simple and immediate way. These graphic communication devices are able to universalize the experience of illness through empathy and compassion [25]. However, just a few studies have investigated the benefits of implementing drawings for consent purposes [26].

The present study was aimed at assessing whether drawings are a communicative method routinely employed in the informative process for consent purposes at University Hospital of Turin and, when used, whether it is inserted in patients' medical records as required by $217 / 19$ Lex. The questionnaire survey focused the attention on the use of this specific graphic way of communication, especially in stressed and urgent situations, such as in cases necessitating invasive procedures, when patients and their families show the most difficulties in comprehending technical terms.

This study is a survey and it was conducted on a sample of reduced numerousness (90 questionnaires). Thus, it could be not fully representative of the whole population considered. Focusing on the results (shown in Panel 1), out of all the doctors who correctly completed the questionnaire, $93.8 \%$ stated to consider drawing an effective means of information for consent acquisition. Of these, just $10 \%$ use standard pre-printed illustrated consent papers, while the majority stated to personally draw images representing the steps of invasive procedures in order to translate very complex technical information in a concrete and immediate visual language. Almost all the physicians who claimed to have drawn themselves images of proposed treatments perceived a real benefit in patients' comprehension when information was shaped in this visual way.

The idea of information as a way of molding something previously shapeless has ancient origins. According to Aristotle, the comprehension of the material world depended upon having mental shapes like ideas, abstractions or concepts; in a similar fashion, Cato the Elder stated "rem tene, verba sequentur" [27], which means that only if you know the concept can you explain it to others. Cicerone used the verb "to inform" to indicate the act of giving structure to something, to form an idea or mold a person's mind. Then, communication can be considered a transfer of information from one shape to another [28]. Illustrations and drawings that concretize abstract concepts, represent a way to convey information through an immediate, visual, non-verbal message [23].

Kearns [29] recently conducted a survey on surgeons' perceptions $(n=100)$ of the use of drawing in their everyday activities; $92 \%$ of the doctors interviewed employing it regularly for communicating and explaining procedures to patients or residents and $82 \%$ of them used it to share post-operative information in a rapid and clear way with colleagues. Even though, in Kearns' study, just $86 \%$ of surgeons deemed drawings useful for improving communication with patients, in the Author's experience up to $93.8 \%$ of the doctors interviewed considered drawing an effective mean of information for consent acquisition given the perceived enhancement in comprehension of the data provided. Medical illustrations, remaining in memory for a longer period of time, are therefore perceived to be a more useful educational tool for conveying immediate understanding than lengthy explanations conducted by a doctor. 
Nonetheless, in this study, just $7 \cdot 4 \%(2 / 27)$ of the clinicians interviewed who personally drew explicative images to patients (almost 90\% of all the doctors of the sample of the study), then added them to medical records. This can be explained by doctors' subjective perceptions of their own limited abilities in drawing and the resultant fear of the possible detrimental effects deriving from an inaccurate illustration from a medico-legal point of view. We have to recognize that informed consent must neither be merely considered a formal act nor a disclosure form or a signature [29]. Information is the main part of the communication process and acts to form a strong therapeutic alliance. Then, since the time dedicated to the communication rightfully belongs to "cure time", inserting an explanatory drawing in medical records certificates that more than one informative modality was used in conveying the information to make it more comprehensible to the specific patient, personalizing the transfer.

Drawing becomes the communication tool by which information is conveyed in a more intuitive and visual way. Drawing can launch the patient's mind into the future and can help him or her to determine their own destiny. According to the Italian civil law system, in cases of damage to the patient's psychophysical integrity resulting from a defect of consent, the hospital charged to pay the monetary compensation must prove that the patient's right to information was not infringed. Therefore, in medico-legal assessment cases of liability for medical error or omission to give information, as reinforced by the sentence of the Supreme Court of Cassation delivered in April 2018 [22], attaching the explicative drawing in clinical records could be proof of the communication time and of the attempt of using, for educational purposes in combination with conventional text and verbal lecture, an easier and visual tool to give shape to the message to transfer it to patients [30].

Recently the Supreme Court of Cassation (Sentence n. 28985/2019) has ulteriorly addressed the issue, confirming the existence of damage to the constitutionally guaranteed right to self-determination in all cases of defect of information about health and therapy, since consent procedures must be considered full-fledged medical acts.

Clinicians and surgeons have not only a deontological and ethical duty in the process of informed consent but also a civil obligation. These three topics are closely interrelated, and the relationship between doctor and patient is unique. Drawing is a tool to attempt to unify them in that moment of uniqueness.

The medico-legal experts may help the patient and doctors in the hospital care setting verifying the patient's comprehension of medical information, with the aim to respect and promote patient's autonomy and prevent medical liability [31].

Therefore, drawings are a tool for humanizing the doctor-patient relationship, molding the content of communication into a more visual shape. Graphical sketch is useful for breaking down comprehension barriers resulting not only from the modality in which the information is conveyed but also from patients' relational, social, cultural and psychological factors, ensuring bi-directionality of communication [1].

\section{Conclusions}

The consent process to any medical act always begins with a detailed dialogue with the doctor. Physicians must be aware that a signed document does not always ensure that patients truly understood [32].

Real comprehension is the most difficult point to achieve for an ethically valid informed consent [33]. It is therefore fundamental to find an alternative way to ensure appropriate understanding [34].
In the present study, physicians are well aware of patients' difficulties in understanding medical information. No wonder $93.8 \%$ of clinicians interviewed revealed using drawings to provide the information, since it has been shown to improve comprehension in $96.3 \%$ of the cases.

Still, $92 \cdot 3 \%$ of the clinicians interviewed did not attach explicative drawings in the medical records of patients. This represents an impediment in proving that this alternative method was used in addition to written and oral information.

Explicative drawings are proof of communicative efforts by physicians in the best interest of the patient, helping to build a trusting relationship.

\section{Conflicts of interest}

None.

\section{Funding}

None.

\section{References}

1. Cargill SS (2019) How Do We Really Communicate? Challenging the Assumptions behind Informed Consent Interventions. Ethics \& human research 41: 23-30.

2. Moeini S, Shahriari M, Shamali M (2020) Ethical Challenges of obtaining informed consent from surgical patients. Nurs Ethics 27: 527-536. [Crossref]

3. Clark S, Mangram A, Ernest D, Lebron R, Peralta L (2011) The informed consent: study of the efficacy of informed consents and the associated role of language barriers. J Surg Educ 68: 143-147. [Crossref]

4. Furuno Y, Hiroyasu S (2015) Medical comics as tools to aid in obtaining informed consent for stroke care. Medicine (Baltimore) 94: e1077. [Crossref]

5. Santovito D, Iorio M, Mastro F, Conforti M, Rispoli P (2007) Symptomatic carotid stenosis. Diagnosis and treatment guidelines Juridical and medico-legal approach. Minerva Cardioangiol 55: 167-98. [Crossref]

6. Mellado JM (2016) Autonomy, consent and responsibility. Part 1: Limitations of the principle of autonomy as a foundation of informed consent. Radiología 58: 343-351. [Crossref]

7. Ciliberti R, Gorini I, Gazzaniga V, De Stefano F, Gulino M (2018) The Italian law on informed consent and advance directives: New rules of conduct for the autonomy of doctors and patients in end-of-life care. J Crit Care 48: 178-182. [Crossref]

8. Abaunza H, Romero K (2004) Elements for adequate informed consent in the surgical context. World J Surg 38: 1594-1604. [Crossref]

9. Fowler JR, Floyd J, Levin CA, Sepucha KR (2011) Informing and involving patients to improve the quality of medical decisions. Health Aff 30: 699-706. [Crossref]

10. https://portale.fnomceo.it/codice-deontologico/

11. King A, Hoppe RB (2013) "Best Practice" for Patient-Centered Communication: A Narrative Review. J Grad Med Educ 5: 385-393. [Crossref]

12. Jefford M, Moore R (2008) Improvement of informed consent and the quality of consent documents. Lancet Oncol 9: 485-493. [Crossref]

13. Gristina GR, Busatta L, Piccinni M (2019) The Italian law on informed consent and advance directives: its impact on intensive care units and the European legal framework. Minerva Anestesiol 85: 401-411. [Crossref]

14. Lentz J, Kennett M, Perlmutter J, Forrest A (2016) Paving the way to a more effective informed consent process: Recommendations from the Clinical Trials Transformation Initiative. Contemp Clin Trials 49: 65-69. [Crossref]

15. Clapp JT, Arriaga A, Murthy S, Raper SE, Schwartz JS, et al. (2019) Surgical Consultation as Social Process. Implications for Shared Decision Making. Ann Surg 269: 446-452. [Crossref]

16. Cocanour CS (2017) Informed consent - It's more than a signature on a piece of paper. Am J Surg 214: 993-997. [Crossref]

17. Morgan DJ, Scherer LD, Korenstein D (2020) Improving Physician Communication About Treatment Decisions: reconsideration of "Risks vs Benefits". JAMA 324: 937938. [Crossref] 
18. Pope TM (2019) Informed consent requires understanding: Complete disclosure is not enough. Am J Bioeth 19: 27-28. [Crossref]

19. Fields LM, Calvert JD (2015) Informed consent procedures with cognitively impaired patients: A review of ethics and best practices. Psychiatry Clin Neurosci 69: 462-471. [Crossref]

20. Slim K, Bazin JE (2019) From informed consent to shared decision-making in surgery. J Visc Surg 156: 181-184. [Crossref]

21. Agozzino E, Borrelli S, Cancellieri M, Carfora FM, Di Lorenzo T, et al. (2019) Does written informed consent adequately inform surgical patients? A cross sectional study. BMC Med Ethics 20:1. [Crossref]

22. Falagas ME, Korbila IP, Giannopoulou KP, Kondilis BK, Peppas G (2009) Informed consent: how much and what do patients understand? Am J Surg 198: 420-435. [Crossref]

23. Court of Cassation, sez III (2018) Sent. 20/04/2018 n. 9806.

24. McNicol S (2014) Humanising illness: presenting health information in educational comics. Med Humanit 40: 49-55. [Crossref]

25. Green MJ, Myers KR (2010) Graphic medicine: use of comics in medical education and patient care. $B M J$ 340: c863. [Crossref]

26. Wheeler R (2017) The evolution of informed consent. Brit J Surg 104: 1119-1120. [Crossref]
27. Iulii Victoris C (1980) Ars Rhetorica, ediderendum. Giomini R (Ed) MS Celentano. Leipzig.

28. Von Baeyer HC (2003) Information. The new language of science. Harvard University Press, $1^{\circ}$ ed.

29. Kearns C (2019) Is drawing a valuable skill in surgical practice? 100 surgeons weigh in. $J$ Vis Commun Med 42: 4-14.

30. Lindor RA, Kunneman M, Hanzel M, Schuur JD, Montori VM, et al. (2016) Liability and informed consent in the context of shared decision making. Acad Emerg Med 23 : 1428-1433. [Crossref]

31. Tattoli L, Dell'Erba A, Ferorelli D, Gasbarro A, Solarino B (2019) Sepsis and Nosocomial Infections: The Role of Medico-Legal Experts in Italy. Antibiotics (Basel) 8: 199. [Crossref]

32. Kim L, Young AJ, Neimeyer RA, Baker JL, Barfield RC (2008) Keeping users at the center: developing a multimedia interface for informed consent. Tech Commun $Q 17$ : 335-357.

33. Marcela GC, Joffe S (2005) Informed consent for medical treatment and research: a review. Oncologist 10: 636-641. [Crossref]

34. Purcaru D, Preda A, Popa D, Moga MA, Rogozea L (2014) Informed consent: how much awarness is there? Plos One 9: e110139. [Crossref]

Copyright: $(02021$ Santovito D. This is an open-access article distributed under the terms of the Creative Commons Attribution License, which permits unrestricted use, distribution, and reproduction in any medium, provided the original author and source are credited. 